\title{
An evaluation of Potts' aortopulmonary shunt for palliation of cyanotic heart disease
}

\author{
F. J. D A NIEL, C. P. CLARKE, J.P. R I CHARDSON, \\ G.W. WESTLAKE, and P. G. JONES \\ Division of Cardiac Surgery, Royal Children's Hospital, Melbourne, Victoria, Australia
}

\begin{abstract}
Daniel, F. J., Clarke, C. P., Richardson, J. P., Westlake, G. W., and Jones, P. G. (1976). Thorax, 31, 394-397. An evaluation of Potts' aortopulmonary shunt for palliation of cyanotic heart disease. The results of 28 Potts' aortopulmonary shunts created for the relief of cyanotic heart disease are reviewed in this study. The shunt gave excellent symptomatic relief, but the incidence of immediate and late complications is high. Regular follow-up of patients is mandatory to detect evidence of increasing pulmonary vascular disease and to undertake corrective surgery whenever feasible before its occurrence.

Although Potts' anastomosis has been largely replaced by alternative shunt procedures, there may still be a place for its application in selected situations. Only a few problems were encountered at the time of closure of the shunt in 11 patients during corrective surgery using a transpulmonary technique and hypothermia with circulatory arrest.
\end{abstract}

In 1946 Potts demonstrated the efficiency of anastomosing the descending aorta to the left pulmonary artery in relieving cyanotic congenital heart disease, and showed it to be especially valuable in young babies in whom a Blalock shunt is not technically feasible. Since that time the procedure has fallen into disfavour because of the difficulties encountered while attempting to close the shunt during subsequent corrective surgery. Although many different techniques of closure have been described, transpulmonary closure using cardiopulmonary bypass, hypothermia, and total circulatory arrest, as advocated by Kirklin and Devloo (1961), is the most popular method.

The present study describes an experience with 28 cases of Potts' anastomosis performed at the Royal Children's Hospital, Melbourne. Particular emphasis is placed on the technique and results of transpulmonary closure of Potts' shunt at the time of total correction of Fallot's tetralogy.

\section{PATIENTS}

A total of 28 patients who were subjected to Potts' anastomosis during the period $1955-65$ are included in the study. Fallot's tetralogy and ventricular septal defect (VSD) with pulmonary atresia formed the major group of patients (25 cases) (Table I).
T A B L E I

\begin{tabular}{|c|c|}
\hline $\begin{array}{l}\text { Total number of cases } \\
\text { Fallot's tetralogy, pulmonary atresia, and VSD } \\
\text { Tricuspid atresia } \\
\text { Double outlet right ventricle and pulmonary } \\
\text { stenosis }\end{array}$ & $\begin{array}{r}28 \\
25 \\
2 \\
1\end{array}$ \\
\hline
\end{tabular}

The ages of the patients at the time of creations of a shunt ranged from 3 months to 6 years, and 11 patients were under 2 years of age. Intraoperative estimation of the size of the shunt varied from 3.0 to $7.0 \mathrm{~mm}$. In one patient with a right-? sided aorta, a right Potts' anastomosis was made. $\frac{D}{2}$

RESULTS OF POTTS' SHUNT

Results following Potts' shunt were divided into three groups. Group 1 included 20 patients whow had satisfactory symptomatic improvement? Patients who died after surgery were put intoo group 2 (8 patients). Revision of the shunt wasD performed in three patients (group 3).

Analysing the fate of group 1, 20 patients were noted to have satisfactory symptomatic improve- $\frac{\text { o }}{D}$ ments (Table II). A large number of patients in this group required at least temporary treatment迎 with digoxin and diuretics. 
T A B L E I I

SYMPTOMATICALLY IMPROVED PATIENTS

\begin{tabular}{l|r} 
Total number & 20 \\
Recatheterized & 14 \\
Further surgery & 13 \\
Total correction of Fallot & 10 \\
VSD and pulmonary atresia (RV outflow & 1 \\
reconstruction) & 1 \\
(ingunde ventricle and pulmonary stenosis & 1 \\
Tricuspid atresia (Glenn shunt) & 1 \\
\hline
\end{tabular}

Fourteen patients of this group were recatheterized 4-11 years after establishment of the shunt. Ten patients had Fallot's tetralogy with favourable anatomy and mild or moderate pulmonary hypertension and were subjected to corrective surgery. One patient had a single ventricle with a single atrioventricular valve and pulmonary stenosis which proved uncorrectable; infundibulectomy was performed as the Potts' shunt had already been ligated. Pulmonary atresia with VSD in one patient was managed by VSD patch closure and reconstruction of the right ventricular outflow tract with a Hancock prosthesis. Tricuspid atresia was noted in one patient, and a Glenn procedure (superior vena cava to right pulmonary artery) anastomosis was undertaken. One patient in this group presented six years after operation with a recurrence of cyanosis and symptomatic deterioration; the previously heard shunt murmur had disappeared, and a chest radiograph showed oligaemic lung fields. Cardiac catheterization revealed severe pulmonary hypertension (pulmonary artery $90 / 64 \mathrm{mmHg}$ and aorta $100 / 70 \mathrm{mmHg}$ ). This case was considered inoperable, and the patient subsequently developed recurrent haemoptyses. The remaining six patients in this group are reviewed regularly and are awaiting repeat study and probable surgery.

Group 2 included all patients who died after a Potts' shunt-a total of eight patients, of whom seven had a necropsy. This group was divided further into those who died in the immediate postoperative period ( 2 cases) and those who died at a later date (six months-three years) (6 cases) (Table III).

Both patients who died within 48 hours developed gross pulmonary oedema within hours of the shunt being established, and they proved resistant to medical treatment. Necropsy examination was performed on both cases and revealed evidence of pulmonary congestion and haemorrhage. In one case the anastomosis measured
T A B L E I I I

MORTALITY AFTER POTTS' SHUNT

\begin{tabular}{|c|c|}
\hline $\begin{array}{l}\text { Died immediately following shunt } \\
\text { Late death } \\
\text { Aneurysm at site of shunt } \\
\text { Cerebral abscess } \\
\text { Associated complex cardiac abnormalities. Died } \\
\text { of progressive cardiac failure }\end{array}$ & 2 \\
\hline
\end{tabular}

$14 \mathrm{~mm}$ at necropsy. Late deaths included six cases, one of whom developed aneurysmal dilatation at the site of anastomosis. This patient died at re-exploration. Cerebral abscess accounted for one death, and associated complex cardiac anomalies with congestive cardiac failure resulted in the death of four patients. Necropsy of seven cases in group 2 revealed evidence of increased pulmonary flow, pulmonary congestion, and varying degrees of pulmonary vascular disease. The histopathological changes were extensive in two cases.

Group 3 consisted of patients in whom revision of the shunt had to be performed ( 3 cases). In one, the anastomosis had to be refashioned soon after surgery because of bleeding, and the size of the anastomosis was $7.0 \mathrm{~mm}$. In two cases the shunt was reduced in size by a silk ligature around the shunt.

\section{RESULTS OF CLOSURE OF POTTS' SHUNT}

Further surgical procedures were performed in 13 patients in group 1 (Table II). Transpulmonary closure was undertaken in 11 patients, and in one the shunt was ligated.

The technique of transpulmonary closure we employed was essentially that of Kirklin and Devloo (1961). Using cardiopulmonary bypass we cooled the patient to $25^{\circ} \mathrm{C}$. The site of the shunt was occluded during this time by external digital pressure over the left pulmonary artery. At $25^{\circ} \mathrm{C}$, the head end of the operating table was lowered by about $20^{\circ}$, the pump was stopped, the left pulmonary artery was opened, and the shunt identified, and sutures were applied to both corners of the shunt. The pump was restarted, and further interrupted sutures were applied to close the shunt. The pulmonary artery was then repaired, a right ventriculotomy was performed, and the aortic valve was tripped through the VSD.

There was no direct mortality attributable to the method of closure of the shunt. However, one patient died after operation due to unrelieved 
right ventricular outflow obstruction. There were no neurological problems in the survivors. A localized stricture of the pulmonary artery at the site of the shunt necessitated patching of the left pulmonary artery in one patient. Closure of the right-sided Potts' shunt was found to be technically difficult. A persistent leak through the shunt was noticed in two patients. One had previously had two attacks of subacute bacterial endocarditis, and closure of the site of the shunt was technically difficult. The leaking Potts' shunt was ligated separately at a later date through a left thoracotomy. In the other patient, the leak is clinically small, and operation is not advised.

\section{DISCUSSION}

The Potts' technique (Potts, Smith, and Gibson, 1946) of descending aorta to pulmonary anastomosis is now an acceptable and reliable procedure in relieving symptoms of cyanotic congenital heart disease (Cole et al., 1971). It is technically easy to perform and can be undertaken in any age group. It is particularly useful in situations where other forms of shunt procedures are technically not feasible.

In spite of the advantages, it is now rarely favoured as a procedure of choice because of complications associated with the establishment of the shunt, and the reported problems encountered at closure of the shunt during corrective surgery.

The majority of complications after establishment of aortopulmonary shunt are due to increased pulmonary blood flow leading to pulmonary oedema, congestive cardiac failure, pulmonary hypertension, development of pulmonary vascular resistance, and blood vessel disease (Ross et al., 1958; McGaff et al., 1962; Kaplan et al., 1968; Bernuth et al., 1971; Cole et al., 1971; Selmonsky et al., 1972). The flow through an aortopulmonary shunt and its effects depend on the size of the shunt and the time it has been present.

In 340 cases of Potts' shunt, Cole and associates (1971) demonstrated a decreased incidence of complications when the size of the shunt was reduced from $8.0 \mathrm{~mm}$ to $4.0 \mathrm{~mm}$ in patients under the age of 2 years. There is evidence that the size of the shunt increases as the child grows (Bernuth et al., 1971). Although a definite correlation between the size of the shunt and the incidence of complications could not be drawn in our study, the size of the shunt was more than $6.0 \mathrm{~mm}$ in all patients who died after surgery.
Ross et al. (1958) documented the occurrence of obstructive pulmonary vascular changes leading? to increased pulmonary vascular resistance in

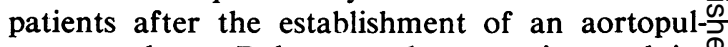
monary shunt. Pulmonary hypertension and in-ฉ creased pulmonary vascular resistance mainlyes determine the outcome at corrective surgery.Bernuth et al. (1971) from the Mayo Clinicdivided their patients into three groups, depending $\vec{\omega}$ on the ratio of pulmonary to systemic flow, and showed that there was no mortality in the group in which pulmonary to systemic resistance ratiow was less than 0.4. As described earlier, catheter studies in one patient who was considered inoper-w able showed severe pulmonary hypertension. Evi- + dence of severe pulmonary vascular disease was을 also seen in two necropsy specimens.

Other complications observed in three patients were an aneurysmal dilatation of the shunt, ac cerebral abscess, and bacterial endocarditis. The mortality rate in the series of Cole et al. (1971) $\overrightarrow{0}$ was $9 \%$ overall with $12-15 \%$ below the age of 2,0 and $3-4 \%$ above the age of 2 years. In our series, there were two deaths in the immediate postopera tive phase and six late deaths. Although six of these cases had associated complex cardiac anon malies, necropsy revealed evidence of increasedळ pulmonary blood flow.

Cole et al. (1971) emphasized the recognition of the potential danger signs of a large left-to-rightshunt; these included complete absence of cyanosiso after anastomosis, a short, low-pitched, rough continuous murmur after operation, progressiveo cardiac enlargement, progressive prominence of the pulmonary artery, marked increase in the pulomonary vascular marking, and biventricular. hypertrophy.

Such signs need careful postoperative evalua tion. The clinical evidence of obstructive pul옥 monary vascular disease includes recurrence of cyanosis and deterioration of symptoms, disap을. pearance of a previously heard murmur, and iso+v lated right ventricular hypertrophy in the presence of pulmonary hypertension (Bernuth et al., 1971) 0 In our series of 28 , three patients had demonew strable evidence of pulmonary vascular disease.

Several techniques have been employed to close the shunt. They included dissection and division ofD the shunt with separate closure of the aorta and ${ }^{+}$ pulmonary artery which has proved to be hazard ous, circumventing the shunt and occluding ifo with a heavy ligature, the use of a mechanica $\frac{P}{8}$ stapler (Leand et al., 1971), and transpulmonary closure under cardiopulmonary bypass, hypo? 
thermia, and circulatory arrest (Kirklin and Devloo, 1961). Gross, Bernhard, and Litwin (1969) reported 53 closures of Potts' shunt at the time of corrective surgery for Fallot's tetralogy. In nine cases ligation of the shunt was attempted. This was technically difficult, and the results were poor. They found their experience with 44 cases of transpulmonary closure was satisfactory. The transpulmonary technique was employed in 11 patients in our series, with no major technical problem related to closure of the shunt.

\section{REFERENCES}

Bernuth, G. Von, Ritter, D. G., Frye, R. L., Weidman, W. H., Davis, G. D., and McGoon, D. C. (1971). Evaluation of patients with tetralogy of Fallot and Potts' anastomosis. American Journal of Cardiology, 25, 259.

Cole, R. B., Muster, A. J., Fixler, D. E., and Paul, M. H. (1971). Long-term results of aorto-pulmonary anastomosis for tetralogy of Fallot. Circulation, 43, 263.

Gross, R. E., Bernhard, W. F., and Litwin, S. B. (1969). Closure of Potts' anastomoses in the total repair of tetralogy of Fallot. Journal of Thoracic and Cardiovascular Surgery, 57, 72-82.

Kaplan, S., Helmsworth, J. A., Ahearn, E. N., Benzing, G., Daoud, G., and Schwartz, D. C. (1968). Results of palliative procedures for tetralogy of Fallot in infants and young children. Annals of Thoracic Surgery, 5, 489.
Kirklin, J. W. and Devloo, R. A. (1961). Hypothermic perfusion and circulatory arrest for surgical correction of tetralogy of Fallot with previously constructed Potts' anastomosis. Diseases of the Chest, 39, 87.

Leand, P. M., Bender, H. W., Jr., Martz, M. N., Crisler, C., Agnew, H. D., and Gott V. L. (1971). A simple method for closure of the Potts' anastomosis with a mechanical stapler. Journal of Thoracic and Cardiovascular Surgery, 62, 285.

McGaff, C. J., Ross, R. S., and Braunwald, E. (1962). The development of elevated pulmonary vascular resistance in man following increased pulmonary blood flow from systemic-pulmonary anastomosis. American Journal of Medicine, 33, 201.

Potts, W. J., Smith, S., and Gibson, S. (1946). Anastomosis of the aorta to a pulmonary artery. Journal of the American Medical Association, 132, 627.

Ross, R. S., Taussig, H. B., and Evans, M. H. (1958). Late hemodynamic complications of anastomotic surgery for treatment of the tetralogy of Fallot. Circulation, 18, 553.

Selmonsky, C. A., Farhangian, D., Folger, G. H., and Ellison, R. G. (1972). Palliative shunting operations in tetralogy of Fallot. Annals of Thoracic Surgery, 14, 16-23.

Requests for reprints to: Dr. F. J. Daniel, Royal Children's Hospital, Flemington Road, Parkville, Victoria 3052, Australia. 